\title{
Genes do not read DSM-IV: implications for psychosis classification
} Nick Stefanis

\author{
Address: 1st Department of Psychiatry, Aeginition Hospital, University of Athens, Greece \\ from International Society on Brain and Behaviour: 3rd International Congress on Brain and Behaviour \\ Thessaloniki, Greece. 28 November - 2 December 2007 \\ Published: 17 April 2008 \\ Annals of General Psychiatry 2008, 7(Suppl I):S68 doi:10.1 I86/1744-859X-7-SI-S68
}

This abstract is available from: http://www.annals-general-psychiatry.com/content/7/SI/S68

(C) 2008 Stefanis; licensee BioMed Central Ltd.

Recent advances in molecular psychiatric genetics have at last identified susceptibility loci for the major psychotic disorders. Not surprisingly several of these genes appear to confer risk not only for schizophrenia but also for schizoaffective, bipolar affective disorder or for "mixed" psychotic phenotypes suggesting an overlap in genetic susceptibility across the traditional Kraepelinian dichotomy. Molecular genetics may catalyze a reappraisal of psychiatric nosology and classification as they challenge the traditionally held notion of distinct psychiatric entities with independent etiology and pathogenesis between the affective and non affective psychoses. Since genes code for proteins that have implications for neuronal microcircuity, and do not directly inflict illness per se, further research should consider deconstructing the broader psychosis phenotype, into measurable components that might be more susceptible to genetic influences than traditionally held DSM-IV Krepelinian dichotomous constructs. We will review the latest evidence for this assertion and present data from the ongoing ASPIS study in which we identified discrete endophenotypes that might be more sensitive to the variability of the recently identified susceptibility genes for psychosis. 